\title{
Obstetric vesico-vaginal fistulae seen in the Northern Democratic Republic of Congo: a descriptive study
}

\author{
Justin L Paluku', Tamar E Carter ${ }^{2}$
}

1. HEAL Africa Tertiary Hospital, Obstetrics and Gynaecology

2. University of Florida, Genetics Institute; University of Florida, Department of Anthropology

\begin{abstract}
Background: The Democratic Republic of Congo (DRC) is a developing country with poor obstetric indicators. Despite ongoing efforts to improve care, women continue to suffer multiple complications of child birth including vesico-vaginal fistulae (VVF).

Objective: To describe socio-demographic and clinical characteristics of VVF patients in Northern DRC.

Methods: Women presenting at two VVF mobile surgical campaign missions in the province of Equateur in Northern DRC in August 2012 and October 2013 were examined and treated for VVF. We collected socio-demographic data, including marital status, education, and accompaniment by husbands for treatment, as a proxy for marital support, and clinical data related to characteristics of VVF in patients, duration of illness, and the outcome of treatment surgery.

Results: Out of 163 VVF patients, $100(61.3 \%)$ were less than 35 years old, 102 had no formal education (62.6\%), and 100 were married (61.3\%). The mean duration of illness before surgery was 8.4 years. Successful surgery rate for VVF was $87.1 \%(142 / 163)$. A majority of patients who were married, were accompanied to the hospital by their husbands for treatment $(56 / 100 ; 56.00 \%)$. Association analysis revealed age was the only variable that maintained significant association with duration of illness after multivariate analysis ( $\mathrm{p}$-value $<0.0001)$. Marital status was the only variable associated with surgical outcome $(0.334,95 \%$ CI 0.125- 0.847, p-value $=0.021)$.

Conclusion: We found that most VVF patients were young adults, not educated, and married. Marital status and age may have important roles in outcome of VVF surgery and duration of illness, respectively.

Keywords: Obstetric vesico-vaginal fistulae, Northern Democratic Republic of Congo

DOI: http://dx.doi.org/10.4314/ahs.v15i4.8

Cite as: Paluku JL, Carter TE. Obstetric vesico-vaginal fistulae seen in the Northern Democratic Republic of Congo: a descriptive study. Afri Health Sci. 2015;15(4):1104-11. bttp:// dx.doi.org/10.4314/abs.v15i4.8
\end{abstract}

\section{Introduction}

The Democratic Republic of Congo (DRC) is one of the developing countries with poor obstetric indicators. Despite ongoing efforts to improve obstetric care ${ }^{1}$, many women continue to suffer multiple complications of child birth. Although a high proportion of deliveries in the DRC occur in a hospital (70\%), many women still give birth at home without any skilled medical assistance. In the province of Equateur in DRC, the majority of births $(59 \%)$ occur at home $e^{2}$. Although hos-
Corresponding author:
Justin L Paluku,
HEAL Africa Tertiary Hospital,
Obstetrics and Gynaecology
Email: justin.healafrica@gmail.com /
jplussy@yahoo.fr

pital delivery does not always guarantee adequate care, home delivery does increase the possibility of obstetric complications.

In general, obstetric complications including fistulae are related to the three delays in receiving appropriate emergency obstetric care: 1) delay in deciding to seek care, 2) delay in reaching health care facilities and 3) delay in accessing quality health care ${ }^{3}$. Women in the DRC in general, and in the province of Equateur in particular, experience these three delays. Poverty exacerbated by many years of insecurity and wars in the DRC, is an important factor that exacerbates these issues and exposes many women to obstetric complications ${ }^{3}$. Among the complications that can occur at delivery are vesico-vaginal fistulae $(\mathrm{VVF})^{4-6}$. 
A vesico-vaginal fistula is an abnormal communication between the bladder and the vagina causing a permanent and involuntary leakage of urine through the vagina ${ }^{6}$. An obstetric vesico-vaginal fistula results from trauma that occurs during the childbirth process. In addition to medical sequelae, a woman with vesico-vaginal fistula is affected in all aspects of her life with substantially reduced quality of life ${ }^{7}$.

Worldwide, the magnitude of the problem of VVF is huge and the actual incidence and prevalence of this disease are not known ${ }^{6}$. It is estimated that 75,000 to 100,000 new cases occur globally each year. However, estimates of the incidence and prevalence of VVF are based on the number of women treated and are therefore likely to be underestimates ${ }^{6,8}$. Very few studies have been conducted on vesico-vaginal fistulae in the world in general ${ }^{6}$ and the DRC in particular.

The current study is one of the few studies conducted in the DRC and the first in the DRC to include both marital status and accompaniment by husbands of VVF patients during the period of treatment. Lwambo ${ }^{9}$ suggested that men have become alienated by the focus on women's trauma and abuse in the DRC and that an increased focus on men in designing human interventions will help women as well by improving the success of the interventions ${ }^{9}$. In the DRC, men are expected to care for their wives and much of their standing in society and their ideas of masculinity are related to the care and protection of their family9. The majority of Eastern DRC men and women are $\operatorname{married}^{8}$ and believe that husbands and wives should not be separated. Furthermore, the vast majority of Eastern Congolese are catholic or protestant (over $70 \%)^{8}$ and both religions believe in the sanctity of marriage. Thus, divorce is rare in the DRC, less than $10 \% .{ }^{8}$ In terms of hospital care, there is only anecdotal evidence that sick women are not typically cared for by their husbands at the hospital, but by other women, e.g. sisters, mothers, aunts.

The goal of this study was to describe socio-demographic and clinical characteristics of VVF patients in Northern DRC and to identify key predictors of duration of illness and outcome of treatment. We were particularly interested in providing empirical data on husband's roles and collected data on marital status and husband's accompaniment of women treated for VVF in our study.

\section{Materials and methods}

\section{Study sites and patient sample description}

This study was conducted during two VVF mobile surgical campaign missions in the province of Equateur in Northern DRC in August 2012 and October 2013. The surgical missions were organized by HEAL Africa, Goma, DRC, a Congolese Christian non-profit organization that cares for vulnerable populations including VVF patients. The first mission was conducted in August 2012 in two general referral missionary hospitals of Tandala and Karawa. These two hospitals are in the same geographic area and serve a relatively homogeneous population living in similar socio-demographic conditions. The second mission was conducted in October 2013 in the general referral missionary hospital of Karawa. In both Tandala and Karawa hospitals, working conditions (operating tables, lighting, etc) are similar and acceptable in an African rural setting. Both missions were conducted by the same medical team. Permission to conduct this study was sought from the HEAL Africa Tertiary Hospital Ethics Committee.

\section{Measuring treatment outcome}

During both missions, patients who presented complaining of uncontrolled leakage of urine were recruited. A medical history was taken for each patient including past obstetrical and gynecological information, past surgical information, and a detailed history of pregnancy and delivery during which the fistula occurred. Additional information on the patient age, height, education, and marital status was recorded. Finally, accompaniment by husband was recorded as a proxy for marital support during illness. Patients were examined by the principal surgeon in the outpatient unit to make the diagnosis of VVF. A dye test was performed to confirm the diagnosis in ambiguous cases.

During the first mission, 91 patients with VVF were identified. Among them, 88 underwent fistula repair. The other three patients with VVF included one case that was complicated by a probable advanced cervical cancer, which benefited from examination under anaesthesia for staging and biopsy. During the second mission, 78 patients were diagnosed with VVF and 75 patients benefited from fistula repair. Among the other three VVF patients, two had irreparable VVF due to extensive damage of the bladder and the urethra. The third patient had VVF complicated by a probable advanced cervical cancer and underwent examination under anaesthesia for staging and biopsy. There were 
no fresh VVF cases where continuous catheter drainage could have been tried.

In total for the two missions, 163/169 VVF patients underwent fistula repair by the same surgeon in the same working conditions. Waaldijk classification was used. Postoperative follow-up of patients was conducted by both the visiting team and local nurses and doctors trained in advance. Two weeks after surgery, a dye test was performed on each patient to confirm closure of the VVF. A cough test was performed on wet patients with a negative dye test to make the diagnosis of urinary incontinence.

\section{Statistical analysis}

We calculated frequency and percent age of each categorical socio-demographic variable (education and marital status) and clinical characteristics of the patients (place of index delivery, type of delivery, outcome of index delivery, surgical history, and outcome of VVF surgery). We calculated mean and standard deviations for continuous variables (age, duration of illness, duration of labor).

We were also interested in whether any of the socio-demographic and pre-surgery clinical features were associated with duration of illness (months) and outcome of treatment (success or failure/incontinence). These variables include marital status, marital accompaniment to treatment, age, education, place of delivery, type of delivery, and outcome of index delivery. Univariate association analysis was performed using Wilcoxon Rank Sum Test (categorical predictor variables) and simple linear regression (age) for duration of illness. Predictors that were significantly associated with either duration of illness were included in multivariate regression analysis. For outcome of treatment, we employed logistic regression reporting odds ratios for measure of effect, and 95\% confidence intervals (CI) intervals and chisquare p-values to assess significance of association. For all tests, $\mathrm{p}$-values less than 0.05 were considered statistically significant. Data were analyzed using SAS 9.2 (SAS Institute, Cary, NC, USA).

\section{Results}

\section{Summary statistics}

Socio-demographic data are presented for the 163 treated obstetric VVF patients (Table 1). Ages of patients ranged between 17 and 65 years, with a mean age of 35 years. More than half of the participants $(92 / 163$; $56.4 \%$ ) were aged 20 to 35 years. The height of the patients ranged from 125 to 176, with a mean of 149.2 $\mathrm{cm}$. Slightly less than half of the VVF patients were less than 150 centimeters, representing $73(44.8 \%)$ patients. One hundred and two patients $(62.6 \%)$ had never been to school.

Table 1. Socio-demographic characteristics of treated obstetric VVF patients $(n=163)$.

\begin{tabular}{lcl}
\hline Variable & Mean & $\begin{array}{l}\text { Standard } \\
\text { Deviation }\end{array}$ \\
\hline Age of patients (years) & 35.2 & 13.1
\end{tabular}

\section{Frequency Percent}

\section{Height of patients (centimeters)}

$\begin{array}{lll}\text { Less than 150 } & 73 & 44.8 \\ \begin{array}{l}\text { Le and above } \\ \text { Level of education }\end{array} & 90 & 55.2 \\ \text { None } & 102 & 62.6 \\ \begin{array}{l}\text { Primary } \\ \text { Secondary }\end{array} \text { Marital status } & 49 & 30.0 \\ \text { Married } & 12 & 7.4 \\ \text { Widowed } & & \\ \text { Divorced } & 100 & 61.3 \\ \text { Single } & 39 & 23.9 \\ & 21 & 12.9 \\ \end{array}$


Clinical characteristics of the patients treated for VVF are listed in Table 2. The mean duration of illness before surgery was 8.4 years. Most of the patients had their index delivery in medical facilities $(135 / 163 ; 82.8 \%)$ with a mean duration of labor of 2.14 days. Of these women, 102 women delivered by caesarean section and 33 delivered vaginally (Table 2). Most of index deliveries resulted in stillbirths $(140 / 163 ; 85.9 \%)$. Among the 163 patients treated for VVF, $150(92.0 \%)$ had never benefited from surgical repair before (Table 2). Out of the 163 patients who underwent VVF surgical repair, 142 (87.1\%) were declared cured, including $10(76.9 \%)$ of the patients previously treated for VVF. Sixteen (9.81\%) patients were not successfully repaired while an additional $5(3.07 \%)$ patients developed post-fistula repair urinary incontinence.

Table 2. Summary statistics for clinical characteristics of patients.

\begin{tabular}{|c|c|c|}
\hline & Mean & Standard Deviation \\
\hline Duration of illness (years, $n=163$ ) & 8.4 & 9.3 \\
\hline \multirow[t]{2}{*}{ Duration of labor (days, $n=163$ ) } & 2.14 & 0.94 \\
\hline & Frequency & Percent \\
\hline \multicolumn{3}{|l|}{ Outcome of VVF surgery } \\
\hline Healed & 142 & 87.1 \\
\hline Failure & 16 & 9.8 \\
\hline Incontinence & 5 & 3.1 \\
\hline Total & 163 & \\
\hline \multicolumn{3}{|l|}{ Previous fistula surgical repair } \\
\hline Yes & 13 & 8.0 \\
\hline No & 150 & 92.0 \\
\hline Total & 163 & \\
\hline \multicolumn{3}{|c|}{ Accompaniment by husband for treatment* } \\
\hline Yes & 56 & 56.0 \\
\hline No & 44 & 44.0 \\
\hline Total & 100 & \\
\hline \multicolumn{3}{|l|}{ Outcome of index delivery } \\
\hline Stillborn & 140 & 85.9 \\
\hline Survived & 23 & 14.1 \\
\hline \multicolumn{3}{|l|}{ Type of delivery } \\
\hline Vaginal & 61 & 37.4 \\
\hline Caesarean & 102 & 62.6 \\
\hline Total & 163 & \\
\hline \multicolumn{3}{|l|}{ Place of delivery } \\
\hline Home & 28 & \\
\hline
\end{tabular}

*Only married individuals included

The majority of VVF patients were married (100/164; $61.0 \%$; Table 1) and 94 married patients were still living with their husbands (data not shown). Of the married women, $56(56.00 \%)$ were accompanied to the hospital by their husbands. None of the women who were not married or not living with their husbands were accompanied to the hospital by their (ex) husbands.
Univariate and multivariate association analysis We were interested in which pre-surgical clinical features and demographic features were associated with either duration of illness or surgical outcome. The variables included in association analysis for duration of illness were marital status, education, age, type of delivery, outcome of index delivery, and accompani- 
Table 4. Comparison of demographic and clinical features across outcome of surgical treatment.

Odds ratios represent chance for failure/incontinence.

\begin{tabular}{|c|c|c|c|c|c|c|c|}
\hline Variable & & Success & $\begin{array}{l}\text { Incontinence/ } \\
\text { Failure }\end{array}$ & Odds Ratio & Lower 95\% & Upper 95\% & P-value \\
\hline \multirow[t]{2}{*}{ Marital Status } & Married & 0.648 & 0.381 & 0.334 & 0.125 & 0.847 & 0.021 \\
\hline & $\begin{array}{l}\text { Not Married } \\
\text { (ref) }\end{array}$ & 0.353 & 0.620 & -- & -- & -- & -- \\
\hline \multirow{3}{*}{$\begin{array}{l}\text { *Accompaniment } \\
\text { by husband for } \\
\text { treatment }\end{array}$} & & & & & & & \\
\hline & Yes & 0.576 & 0.375 & 2.265 & 0.511 & 10.049 & 0.273 \\
\hline & No (ref) & 0.424 & 0.625 & -- & -- & -- & -- \\
\hline \multirow[t]{3}{*}{ Education } & None (ref) & 0.641 & 0.524 & -- & -- & -- & -- \\
\hline & Primary & 0.296 & 0.334 & 1.379 & 0.478 & 3.756 & 0.54 \\
\hline & Secondary & 0.064 & 0.143 & 2.758 & 0.552 & 10.973 & 0.197 \\
\hline \multirow[t]{3}{*}{ Type of Delivery } & $\begin{array}{l}\text { Vaginal } \\
\text { (ref) }\end{array}$ & 0.395 & 0.239 & 0.48 & 0.167 & 1.384 & 0.175 \\
\hline & Cesarean & 0.606 & 0.762 & -- & -- & -- & -- \\
\hline & & $\begin{array}{l}\text { Success } \\
35.14\end{array}$ & $\begin{array}{l}\text { Incontinence/ } \\
\text { Failure }\end{array}$ & Odds Ratio & Lower 95\% & Upper 95\% & P-value \\
\hline Age & & $(12.97)^{*}$ & $36.19(14.33)^{*}$ & 1.006008 & 0.970319 & 1.03984 & 0.7313 \\
\hline
\end{tabular}

*Standard deviations are listed in parenthesis.

Associations between outcome of treatment with pre-surgical clinical and demographic features were also explored. The variables included as predictors in these analysis include marital status, education, age, type of delivery, and marital accompaniment. Results of univariate analysis using simple logistic regression are shown in Table 5, which includes effect size (ie. odds ratios), $95 \%$ confidence intervals, and chi-square p-values. Only marital status was significantly associated with surgical outcome (odds ratio 0.334, 95\% CI 0.125- 0.847, p-value $=0.021)$, in that individuals who were married were more likely to have a successful surgical outcome.

Table 5. Multiple linear regression for duration of illness.

\begin{tabular}{llcc}
\hline & & Parameter & \\
Variable & Term & $\begin{array}{l}\text { Estimate } \\
\text { P-value }\end{array}$ \\
\hline $\begin{array}{l}\text { Marital Status (Married/not } \\
\text { married) }\end{array}$ & Intercept & -41.55978646 & 0.076 \\
Education & & & \\
& None & 14.2437394 & 0.0788 \\
Age & Primary & 10.36117929 & 0.4396 \\
& Secondary (ref) & 1.407926203 & 0.92 \\
& & & \\
\hline
\end{tabular}




\section{Discussion}

The purpose of our study was to describe both socio-demographic and clinical characteristics of VVF cases studied from two clinics in the DRC. There is no specific age at which an obstetric fistula may occur and a woman may develop an obstetric fistula at any age if she does not have a safe delivery. Poor management of prolonged obstructed labor is known to be a primary cause of obstetric fistula in developing countries ${ }^{3-5}$. Nearly half of the patients operated for VVF were less than 150 centimeters tall. Short stature women are more likely to develop obstructed labor ${ }^{5}$. In developing countries, it is believed that several other factors contribute to the development of a fistula, including early marriage, poverty, lack of education and chronic malnutrition which limits the height and weight growth ${ }^{3}$ in women and leads to a high risk of dystocia due to foeto-pelvic disproportion and/or malpresentation ${ }^{4,5,7}$. As shown in previous studies ${ }^{5}$, most patients in our study had never attended school most likely due to poverty and scarcity of schools in the province of Equateur and local cultural behavior.

Most patients in our study delivered by caesarean section. High rates of caesarean deliveries have been reported among VVF patients in other sub-Saharan countries $^{10-12}$. Generally lack of timely access to quality emergency obstetric care is among the leading factors to formation of VVF, especially lack of skilled birth attendants to perform safe caesarian sections and delayed decision-making to perform a caesarean section when labor is obstructed. Prompt diagnosis and safe and timely intervention to deal with obstructed labor is crucial to avoid fistula. Hawkins $L$ et al reported that patients with obstetric fistula typically have an index labor lasting more than two days due to poor access to emergency obstetric care ${ }^{3}$.Vaginal deliveries were also not safely conducted. Among 61 obstetric VVF patients who reported vaginal deliveries, 28 delivered at their homes while 33 delivered in hospitals. The high number of fistulae from hospital vaginal deliveries suggests that birth attendants may have failed to safely conduct vaginal deliveries or that patients may have presented in hospitals very late in labor when the process of fistula formation was at an irreversible stage. Similar findings have been reported in previous studies in other African settings ${ }^{11}$ and poor access to quality obstetric care has been identified another major factor for fistula forma$\operatorname{tion}^{12,3}$.
In this study, most of babies born from VVF patients during index deliveries did not survive. Several studies from other developing countries report very high perinatal deaths in VVF index deliveries. ${ }^{13,14}$ Majority of patients in our study had never benefited from any surgical repair before and our surgical repair success rate was high. Generally there are very few skilled fistula surgeons in developing countries including in the DRC. This leads to an immense backlog of women with obstetric fistula yet to receive surgical management. To address this deficiency in resources and skills, the International Federation of Obstetricians and Gynaecologists (FIGO) and the United Nations Population Fund (FNUAP) have developed a standardized training program to enable more physicians to prevent and treat obstetric fistulae ${ }^{3}$. Also previous studies reported that primary repair of obstetric fistula has more success ${ }^{3,15}$.

We were particularly interested in the potential role that marital status played in duration of illness. Previous studies have shown that obstetric fistulae are associated with social consequences including divorce ${ }^{4,5,16}$. Our study is the first to investigate the association of VVF and husband involvement in their wives' treatment in the DRC. Most of our patients in the study were married $(60 \%)$. While marital status was not associated with duration of illness after accounting for age and education, marital status was the only variable associated with outcome of treatment. We show that married patients more likely to have successful treatment outcomes.

We also looked at the frequency of husband's accompanying their wives for treatment as a proxy for marital support and found that most married women still living with their husbands were accompanied by their husbands to the hospital for their VVF treatment (56\%). A previous study in Ethiopia reported only $25.5 \%$ of patients with fistula were accompanied by their husbands to Addis Ababa Fistula Hospital ${ }^{17}$. Unlike marital status, accompaniment by husbands to VVF treatment was not directly associated with either duration of illness or outcome of treatment, though additional studies with larger samples sizes should be employed to confidently rule out the role of husband support VVF related clinical features.

In addition to marital status and accompaniment by husband to treatment, we also described general characteristics of our VVF patient sample. In our study, pa- 
tients' ages ranged from 17 to 65 years, with the majority of patients aged between 20 and 35 years. Only eight women ( $4 \%$ of the population) were under 20 years old although previous studies suggest that most patients with obstetric fistula are young ${ }^{7,18}$ and that young mothers are at high risk of developing obstetric fistula due to a higher risk of obstruction during labor ${ }^{19}$. The range of ages (17-65 years) suggests that some women in the study may have suffered with the disease for a very long time. Indeed, we find that age is positively associated with duration of illness. This lack of treatment is likely due to inaccessibility of health care and lack of fistula surgeons in the region. Studies have showed that although the prevalence of obstetric fistula is high in developing countries ${ }^{4-6}$, there are very few trained fistula surgeons in the world ${ }^{6}$. This applies to the DRC in general and to the province of Equateur in particular.

\section{Conclusion}

We found that a majority of VVF patients that were young adults, short in stature, and not educated. Most VVF patients had caesarean section deliveries and VVF cure rate was quite high $(87.1 \%)$. The study also showed that a slight majority of VVF patients were married and accompanied by their husbands throughout their hospital stay $(56.00 \%)$. Finally, we found that age was an important indicator for duration of illness and marital status for outcome of surgical treatment.

\section{References}

1. Lalonde AB, Senikas V, Bateson DS, Perron L. SOGC Partnership Program 1998-2006: building organization capacity to support improved maternal and neonatal health. J Obstet Gynaecol Can. 2008;30(11):1014-1024.

2. Epidemiologic and Health survey - Democratic Republic of Congo. 2008.

3. Hawkins L, Spitzer RF, Christoffersen-Deb A, Leah J, Mabeya H. Characteristics and surgical success of patients presenting for repair of obstetric fistula in western Kenya. International Journal of Gynecology \& Obstetrics. 2013;120(2):178-182.

4. Alio AP, Merrell L, Roxburgh K, et al. The psychosocial impact of vesico-vaginal fistula in Niger. Arch Gynecol Obstet. 2011;284(2):371-378.

5. Tafesse B, Muleta M, Michael AW, Aytenfesu H. Obstetric fistula and its physical, social and psychological dimension: the Ethiopian scenario. Acta Urol. 2006;23:25-31.

6. Elneil S, Patel N, Rushwan H, et al. Global competency-based fistula surgery training manual. FIGO House, Suite. 2011;3.
7. Spurlock J. Vesicovaginal fistula [Internet].[updated 2009 Oct 1].

8. Slegh H, Barker G, Ruratotoye B, Shand T. Gender relations, sexual violence and the effects of conflict on women and men in North Kivu, Eastern Democratic Republic of Congo: preliminary results of the international men and gender equality survey (IMAGES). Sonke Gender Justice Network and Promundo-US: Cape Town, South Africa, and Washington, DC. 2012.

9. Lwambo D. 'Before the war, I was a man': men and masculinities in the Eastern Democratic Republic of Congo. Gender \& Development. 2013;21(1):47-66.

10. Tebeu PM, De Bernis L, Doh AS, Rochat CH, Delvaux T. Risk factors for obstetric fistula in the Far North Province of Cameroon. International Journal of Gynecology \& Obstetrics. 2009;107(1):12-15.

11. Wall LL. Overcoming phase 1 delays: the critical component of obstetric fistula prevention programs in resource-poor countries. $B M C$ pregnancy and childbirth. 2012;12(1):68.

12. Washington BB, Raker CA, Kabeja GA, Kay A, Hampton BS. Demographic and delivery characteristics associated with obstetric fistula in Kigali, Rwanda. International Journal of Gynecology \& Obstetrics. 2015;129(1):3437.

13. Nafiou I, Idrissa A, Ghaichatou A, Roenneburg M, Wheeless C, Genadry RR. Obstetric vesico-vaginal fistulas at the National Hospital of Niamey, Niger. International Journal of Gynecology \& Obstetrics. 2007;99:S71-S74. 14. Wall LL, Karshima JA, Kirschner C, Arrowsmith SD. The obstetric vesicovaginal fistula: characteristics of 899 patients from Jos, Nigeria. American Journal of Obstetrics and Gynecology. 2004;190(4):1011-1016.

15. Creanga A, Genadry RR. Obstetric fistulas: a clinical review. International Journal of Gynecology \& Obstetrics. 2007;99:S40-S46.

16. Murphy M. Social consequences of vesico-vaginal fistula in northern Nigeria. Journal of biosocial science. 1981;13(02):139-150.

17. Muleta M, Rasmussen S, Kiserud T. Obstetric fistula in 14,928 Ethiopian women. Acta obstetricia et gynecologica Scandinavica. 2010;89(7):945-951.

18. Meyer L, Ascher-Walsh CJ, Norman R, et al. Commonalities among women who experienced vesicovaginal fistulae as a result of obstetric trauma in Niger: results from a survey given at the National Hospital Fistula Center, Niamey, Niger. American journal of obstetrics and gynecology. 2007;197(1):90. e91-90. e94.

19. Cook RJ, Dickens BM, Syed S. Obstetric fistula: the challenge to human rights. International Journal of Gynecology \& Obstetrics. 2004;87(1):72-77. 